\title{
ELEMENTOS FANTÁSTICOS Y SIMBÓLICOS EN “TIEMPO DESTROZADO” Y "EL ESPEJO” DE AMPARO DÁVILA
}

\author{
Iram Isaí Evangelista Ávila \\ Universidad Autónoma de Chihuahua \\ ievangelista@uach.mx
}

Resumen: El presente artículo realiza un ejercicio de interpretación en torno a elementos relacionados con lo fantástico y lo simbólico en dos cuentos de Amparo Dávila, "Tiempo destrozado" y "El espejo". En lo concerniente a lo fantástico, nos apoyaremos en las definiciones de H. P. Lovecraft (2014) y David Roas (2001; 2009). La conceptualización del símbolo se fundamenta en la teoría de Paul Ricœur (2003) y Mauricio Beuchot (2007). El análisis se halla en el entrecruce de lo fantástico y lo simbólico, mediante un ejercicio interpretativo el cual sirve como medio para desentrañar los mecanismos del entramado narrativo daviliano. Se expone que lo simbólico dentro de la trama se desenvuelve como un epicentro que necesita lo fantástico para transgredir la realidad de los protagonistas.

Palabras clave: lo fantástico, lo simbólico, configuración, cuento, interpretación, Amparo Dávila.

\section{WEIRD AND SIMBOLIC ELEMENTS IN AMPARO DÁVILA'S "TIEMPO DESTROZADO" AND "EL ESPEJO"}

\begin{abstract}
The purpose of this article is to carry out an interpretation of elements related to the Weird and the symbolic in two of Amparo Davila's short stories, "Tiempo destrozado" and "El espejo". In terms of the Weird, the study is based on the definitions by H. P. Lovecraft and David Roas $(2001 ; 2009)$. Regarding the symbolic, the concepts are taken from the theoretical work of Paul Ricœur (2003) and Mauricio Beuchot (2007). The analysis works in the overlapping of the Weird and the symbolic through an interpretative exercise that unearths the mechanisms of the Davilian narrative scaffolding. It is concluded that the symbolic in the plot develops like an epicentre that requires the Weird to undermine the protagonists' reality.
\end{abstract}

Keywords: the Weird, the symbolic, configuration, short story, interpretation, Amparo Dávila.

DOI: https://doi.org/10.24029/lejana.2020.14.936

Recibido: el 28 de agosto de 2020

Aceptado: el 9 de diciembre de 2020

Publicado: el 26 de febrero de 2021 


\section{Introducción}

Amparo Dávila, nacida en Pinos, Zacatecas, México, el 21 de febrero de 1928, muestra en su cuentística cómo lo fantástico y lo simbólico se configuran en propuestas interpretativas de las cuales dispone para crear su arte literario. Lo anterior sirve para plantear el análisis de la ruptura del tiempo como situación lineal o como unidad dentro del relato "Tiempo destrozado". La estructura de este cuento quiebra dicha linealidad temporal tanto en la trama como en la lectura misma. A propósito de la trama de "El espejo", se expondrá una explicación sobre los antagonistas (el propio espejo como símbolo y un acercamiento a los seres que salen de él) y su influjo hacia los personajes principales que son una madre y su hijo. La trama expone el decaimiento físico y psicológico de los protagonistas mencionados, los cuales caen bajo la influencia de un espejo que se encuentra en el cuarto de un hospital. En otra aproximación del mismo cuento se toma al espejo como un símbolo de los riesgos de una relación codependiente. ${ }^{1}$ Los lineamientos conceptuales irán de la mano de autores como Howard Phillips Lovecraft, Paul Ricœur, Norbert Elias y la propia narradora mexicana Amparo Dávila.

Para el uso del término fantástico, el trabajo se remite a un paralelismo con el concepto Weird, ${ }^{2}$ ya que ambos términos hacen referencia a lo que el escritor estadounidense Howard Phillips Lovecraft describe como "Una cierta atmósfera de fuerzas desconocidas, opresivas e inexplicables (que) deben estar presentes" (2014: 1), y añade un estímulo aparte: "Esa gran y terrible concepción del pensamiento humano: una maligna y singular supresión o derrota de esas leyes fijas de la naturaleza, las cuales son nuestra única seguridad en contra de los asaltos del caos y los demonios del espacio insondable" (2014: 1). ${ }^{3}$ Además, nos apoyamos en los criterios que define David Roas, quien igualmente puntualiza la similitud entre los dos términos: "La inmensa mayoría de las teorías sobre lo fantástico define dicha categoría a partir de la confrontación entre dos instancias fundamentales: lo real y lo imposible (o sus sinónimos: sobrenatural, irreal, anormal, etc.)" (2009: 94). Las definiciones anteriores serán base para analizar los procedimientos discursivos propios de los dos cuentos mencionados de Amparo Dávila.

\footnotetext{
${ }^{1}$ Para agilizar la lectura de la introducción, la explicación de la trama de "Tiempo destrozado" y de "El espejo" se hará en sus respectivos apartados.

${ }^{2}$ En la traducción de Introducción a la literatura fantástica de Todorov que se utiliza en este artículo, aparece en voz del autor búlgaro-francés la siguiente cita textual de Lovecraft: "Un cuento es fantástico, simplemente si el lector experimenta en forma profunda un sentimiento de temor y terror, la presencia de mundos y de potencias insólitos" (2018: 26; itálicas mías). El trabajo actual utiliza la misma fuente de Lovecraft citada en Introducción..., la cual es Supernatural Horror in Literature, pero en inglés original se lee "The one test of the really weird is simply this whether of not there be excited in the reader a profound sense of dread, and of contact with unknown spheres and Powers" (2014: 1). Notamos que en la traducción al español se utiliza el término "fantástico" como un equivalente al término Weird. Por ello, este trabajo propone la analogía existente entre ambos términos.

3 "A certain atmosphere of breathless and unexplainable dread of outer, unknown forces must be present; [...] of that most terrible conception of the human brain - a malign and particular suspension or defeat of those fixed laws of Nature which are our only safeguard against the assaults of chaos and the daemons of unplumbed space". Traducción propia.
} 
Esta presencia antagónica de lo real y lo imposible en la obra de Amparo Dávila se constituye de elementos que se pueden manifestar dentro de la cotidianidad. Es en esta cotidianidad donde surge la ruptura de las leyes de la naturaleza y, a través de ella, también surge

Lo innombrable, como lo llamó el genio de Providence, encuentra su representación arquetípica en las criaturas invisibles; no en los fantasmas o espíritus de los muertos, sino en aquellas presencias sin categorizar, cuya sola percepción - amenazas efectivas al margen- pone en jaque la cordura del narrador y nos deja a los receptores en la sombra, bien sugestionados por la inmensidad de lo que sentimos en las palabras de aquel, bien dudando de si lo que nos ha contado no es sino producto de su imaginación desquiciada. (Carrera Garrido, 2018: 193-194)

Estas entidades davilianas manifiestan su presencia como antagonistas invisibles que afectan lo rutinario y, con ello, la estabilidad emocional de los personajes. Esta disposición del cuento fantástico que Amparo Dávila maneja en su obra es parte de como percibe ella su realidad:

Para mí la realidad, al igual que una moneda, tiene dos caras: la cara externa o transparente en donde todas las cosas que suceden pueden entenderse y explicarse, tienen un sentido y una lógica, y la cara interna, la más íntima y profunda, oscura y misteriosa donde a veces ocurren esas cosas extrañas que no tienen explicación ni lógica, que no se pueden aclarar ni comprender pero que suceden. Yo manejo estas dos caras de la realidad, voy y vengo de una a otra fácilmente. (Dávila, citado por Seong, 2009: 5)

Para la escritora, la realidad se conforma de dos planos: uno con una lógica comprensible y explicable; otro misterioso e indescifrable. Es en la comunión de estos dos lados donde se genera la significación de su obra.

Esta concepción de la realidad que nos ofrece Amparo Dávila es abordable mediante la propuesta en torno al símbolo de Paul Ricœur en El conflicto de las interpretaciones: "Llamo símbolo a toda estructura de significación donde un sentido directo, primario y literal designa por añadidura otro sentido indirecto, secundario y figurado, que sólo puede ser aprehendido a través del primero" (2003: 17). De esta manera, la propuesta del teórico es apta para la comprensión de la visión de la narradora: para Ricœur existe un lado referente y otro oculto que forman una significación completa. Para Dávila, la conjunción de elementos comprensibles e incomprensibles conforma la realidad como tal. Por un lado, está lo que podemos entender de manera lógica; por el otro lado, yace lo oculto. Así, lo que se presenta de forma clara y ordenada es interpretable de forma directa, mientras que lo inexplicable nos llama a descubrirlo. Solo al unir ambas caras podemos lograr aproximarnos a la complejidad de la significación del relato. A través de lo referente se llega a lo oculto; lo oculto, a su vez, resignifica lo referencial. Este ir y venir entre significaciones nos traza un sendero donde tanto lo fantástico y lo cotidiano comprenden la estructura del relato. En "Tiempo destrozado" y "El espejo", surgen elementos que cumplen con las concepciones de la autora y que son interpretables desde la dualidad simbólica propuesta por Ricœur. Miguel Carrera Garrido encuentra también este aspecto simbólico dentro de la cuentística de Amparo Dávila y lo menciona como "Algo indefinible, inasible que, por estos mismos atributos, se sugiere más perturbador, más irremediable, pero, a la vez, más rico en el eje simbólico" (2018: 200). Por un lado, el tiempo que se nos presenta como 
el antagonista fantástico y que posee su simbología; por otro, el espejo, que como elemento opuesto a los personajes del cuento se manifiesta a través de sus dos caras: lo que se ve y lo que se oculta. Ambas narraciones guardan en su arquitectura el convivir y la costumbre, trastocados por lo oculto y lo fantástico. Estos elementos se pondrán en relieve en el análisis propuesto.

A continuación, se enuncia lo que entenderemos por Tiempo. Para Norbert Elias, en su libro Sobre el tiempo este concepto se define de la siguiente manera:

El tiempo es único, porque utiliza símbolos — principalmente numéricos, en el actual estadiopara orientar en el incesante flujo del acontecer, en la sucesión de los eventos, en todos los niveles de integración: físico, biológico, social e individual. [...] Al ver el reloj sé qué hora es, no sólo para mí sino para toda la sociedad a la que pertenezco. Los símbolos de la esfera del reloj me informan además de los aspectos del acontecer natural: la posición actual del Sol y la Tierra en la inacabable sucesión de sus movimientos. Me responden a la pregunta de si ahora es de mañana o de tarde, de día o de noche. Como se ve, en el estadio presente del desarrollo, el tiempo se ha convertido en símbolo de un amplio entramado de relaciones, donde se entreverán los procesos de niveles diversos: el individual, el social, el natural inhumano. (1989: 24)

De lo anterior quisiera dar un mayor peso al aspecto de cómo "el tiempo se ha convertido en símbolo de un amplio entramado de relaciones" (Elias, 1989: 24) antes que una definición propiamente tal, pues como dijera la clásica línea de Agustín de Hipona, “¿Qué es, pues, el tiempo? Si nadie me lo pregunta, lo sé; pero si quiero explicárselo al que me lo pregunta, no lo sé” (2015: 118). Este tiempo devenido en símbolo nos permite preguntar: ¿Por qué el tiempo se convierte en un antagonista fantástico? Precisamente para ver por qué el tiempo presentado por la autora es destrozado, nos sirve de ejemplo el inicio de los párrafos 1, 2, 3 y 4 del cuento:

Primero fue un inmenso dolor. Un irse desgajando en el silencio. Desarticulándose en el viento oscuro. Sacar de pronto las raíces y quedarse sin apoyo. (Dávila, 2009: 65, párr.1)

Entramos en la Huerta Vieja, mi padre, mi madre y yo. La puerta estaba abierta cuando llegamos y no había perros ni hortelano. (Dávila, 2009: 65, párr. 2)

Un árabe vendía telas finas en un cuarto grande lleno de casilleros. (Dávila, 2009: 66, párr. 3)

Sangre, ¡qué feo el olor de la sangre! Tibia, pegajosa, la cogí y me horroricé. (Dávila, 2009: 68, párr. 4)

El primer párrafo nos cuenta el descenso de la protagonista a un lugar límbico, sin hacer alusión a alguna edad específica de la misma; en el segundo, el personaje se describe como una niña y cuenta su trágica caída a un estanque; en el tercero, la protagonista se presenta como una mujer adulta que está comprando telas; finalmente, en el cuarto, mediante quiebre temporal, aparece de nueva cuenta en su niñez. Es así que, dentro de la trama, no existe esta concepción que nos explica Norbert Elias. Este símbolo que Elias define, el cual integra lo "físico, biológico, social e individual" (1989: 24) es lo primero que se desarticula para la narradora en "Tiempo destrozado". ¿Es de mañana o de tarde; hoy, ayer o mañana; este mes o hace varios años? No sabemos, el suceder de los elementos lineales se quiebra dentro del mundo descrito. Lo anterior comulga de 
manera cabal con la fórmula citada de Lovecraft: "supresión o derrota de esas leyes fijas de la naturaleza" (2014: 1).

\section{Una propuesta para "burlar" o "destrozar" el tiempo}

"Tiempo destrozado" comienza in extrema res: "Primero fue un inmenso dolor. Un irse desgajando en el silencio" (Dávila, 2009: 65); esta entrada del texto nos da el primer guiño de la propuesta del cuento, donde un comienzo surge de un final y viceversa, es decir, desde el inicio de la narración, el juego con la linealidad del tiempo, el que consideramos "normal", se trastoca por el enfrentamiento de una secuencia de un flujo "anormal" del acontecer: "Insisto, pues, en que lo fantástico exige constantemente que el fenómeno descrito sea contrastado tanto con la lógica construida en el texto como con esa otra lógica — también construida - que es nuestra visión de lo real" (Roas, 2001: 27). Además, cada párrafo narra sucesos a manera de "saltos" en la temporalidad del cuento, no existe una continuidad, "un acontecer natural" como lo menciona Norbert Elias, sino que se nos muestra precisamente, como una "supresión de las leyes de la naturaleza". Así, no solamente nos ofrece una posibilidad de quebrar el tiempo en la lectura, sino que el propio narrador-personaje comienza a "destrozar" el tiempo como una posibilidad dentro de la trama, debido a que no sigue una consecuencia lineal en sus acciones, sino que primero presenta su entrada a otra realidad, narra su niñez y a partir de ahí comienza a dar saltos hasta su vejez. Mas esto no se presenta como una mera estrategia o técnica narrativa, un recurso de discontinuidad en el acto de narrar: es, además, una representación de la realidad del personaje.

Esta disposición de los hechos comprende un desafío y un desenvolvimiento fuera de lo que llamamos natural. Se trata de "la ruptura o subversión (sorprendente e inexplicable) de la casualidad ordinaria accediendo a dimensiones ocultas, mundos paralelos o a un orden temporal o espacial diferente al actual" (Herrero Cecilia, 2000: 50-51). Surge, entonces, una doble asimilación que hacemos del tiempo. Por un lado, se presenta el natural y medible; por otro, se manifiesta como el antagonista fantástico. Así, se constituye entonces en un símbolo que funge como antagonista en el cuento de Amparo Dávila.

Partiendo de lo anterior, trataremos de poner en relieve la forma en que, a través de la narración, el tiempo puede evadirse hacia una vida posiblemente eterna, dando como resultado un tiempo burlado o un tiempo destrozado. Cuando la narradora-personaje relata los hechos, comienza describiendo su descenso hacia otro plano diferente a la vida mortal: "El mundo físico y el mundo espiritual se interpenetran; sus categorías fundamentales se encuentran, por lo tanto, modificadas. El tiempo y el espacio del mundo sobrenatural, tal como están descritos en este grupo de textos fantásticos, no son el tiempo y el espacio de la vida cotidiana" (Todorov, 2018: 87). Por ello, el siguiente párrafo introductorio lo tomaremos como parte del símbolo de una vida que no responde a las leyes del tiempo como lo conocemos: "físico, biológico, social e individual" (Elias, 1989: 24). Recordemos que, para Ricœur, el símbolo manifiesta un sentido referencial. Aquí podemos hablar de que dicho sentido se explica como la vida habitual o la vida sustentada en la realidad como la conocemos. El otro plano, el oscuro y misterioso, se explica de 
otra forma. El relato propone un descenso a otra etapa distinta a la mortal o a un plano onírico sin despertar, el cual puede tomarse como un equivalente a un escape de la vida ordinaria y lineal:

Primero fue un inmenso dolor. Un irse desgajando en el silencio. Desarticulándose en el viento oscuro. Sacar de pronto las raíces y quedarse sin apoyo, sordamente cayendo. Despeñándose de una cima muy alta. Un recuerdo, una visión, un rostro, el rostro del silencio, del agua. [...] Todo fue ligero entonces y gaseoso. La sustancia fue el humo, o el sueño, la niebla que se vuelve irrealidad. Todo era instante. Se podía tocar el techo con las manos, o traspasarlo, o quedarse flotando a medio cuarto. Subir y bajar como movido por un resorte invisible. Y todo más allá del sonido; donde los pasos no escuchan sus huellas. Se podía llegar a través de los muros. Se podía reír o llorar, gritar desesperadamente y ni siquiera uno mismo se oía. Nada tenía valor sino el recuerdo. El instante sin fin estaba desierto, sin espectadores que aplaudieran, sin gritos. Nada ni nadie para responder. Los espejos permanecían mudos. No reflejaban luz, sombra ni fuego. (Dávila, 2009: 65)

Este primer párrafo nos da tablas para soportar la idea de que la narradora-protagonista se encuentra en un estado etéreo, evanescente, donde su estadio se torna pasajero. El paso a otra vida donde lo material se esfuma. La cita anterior muestra semejanza a la descripción que hace Dante a su llegada al limbo: "El abismo era tan profundo, obscuro y nebuloso, que en vano fijaba mis ojos en su fondo, pues no distinguía cosa alguna. [...] Allí, según pude advertir, no se oían quejas, sino sólo suspiros" (Alighieri, 2003: 31); este fragmento elabora paralelismo con "No reflejaban luz, sombra ni fuego" de la narradora. Existe entonces base para sostener que este lugar límbico es la antesala del sendero de la protagonista hacia otra instancia de la vida y que dentro de este lugar se suspende la marcha del tiempo. Este paralelismo entre el espacio daviliano y la obra del poeta florentino también lo nota Lidia García Cárdenas en "El simbolismo del espacio en Tiempo destrozado" donde apunta: "Los demonios de Dante Alighieri, también deambulan en la producción narrativa de Amparo Dávila y, de igual modo, hay vínculos con la selva oscura, la entrada al averno, la barca de Caronte y los nueve círculos del dantesco infierno" (2010: 152).

Si en el primer párrafo la narradora nos describe el estado límbico, en el segundo nos cuenta el ingreso a otra vida, pero cuando era una niña, esto aduce a los "saltos" o "quiebres" temporales. De manera que esta narración comienza a hacerse atemporal, fracturada, coincidiendo con la siguiente idea todoroviana: "si lo fantástico aparece es porque precisamente los indicios de lo sobrenatural son observados por el propio narrador" (Todorov, 2018: 61). La protagonista nos detalla el accidente sufrido por desear una manzana roja que se encuentra en el fondo de un estanque, este suceso nos sugiere una filiación intertextual con el Génesis, la expulsión de Eva del paraíso y la posterior consecuencia de la caída que es el recibimiento de la muerte terrenal:

Me solté de las manos de mis padres y corrí hasta la orilla del estanque. En el fondo había manzanas rojas y redondas... quería verlas bien... me acerqué más al borde... más... —No, hija, que te puedes caer — gritó mi padre. Me volví a mirarlos. Mamá había tirado la cesta y se llevaba las manos a la cara, gritando. - Yo quiero una manzana, papá. - Las manzanas son un enigma, niña - Yo quiero una manzana grande y roja, como ésas... - No, niña, espera... yo te buscaré otra manzana. Brinqué adentro del estanque. (Dávila, 2009: 66) 
Pero caer en el estanque es también el origen de su nueva vida:

Sentí un terrible ardor en la garganta... papá, mamá... papá, mamá... yo tenía la culpa. Salí fuera del estanque. Ya no estaban allí. Habían desaparecido con el viento y con el agua... comencé a llorar desesperada... se habían ido... tenía miedo y frío... los había perdido, los había perdido y yo tenía la culpa... estaba oscureciendo... tenía miedo y frío... mi papá, mi mamá... miré hacia abajo; el fondo del estanque era un gran charco de sangre... (Dávila, 2009:66)

Aquí comienza el reto de la protagonista, el cual consiste en imponer su trayecto a los designios del acontecer lineal. Su entrada al otro mundo, a ese mundo donde el tiempo no es lineal, se da por medio del fin de su trayecto mortal, logra escapar de la vida mortal entrando y después saliendo por el mismo estanque donde había caído por ir tras la manzana. El agua, fuente de vida, une lo físico con la estadía etérea.

La protagonista cae al estanque siendo una niña; sin embargo, en el lapso que permanece sumergida dentro del vital líquido, salta a su ciclo de madurez. Lo sabemos porque así la describe el personaje árabe que al momento de verla la menciona como "Señora". Ya no es la niña, sino una mujer. El tiempo lineal ha sufrido una distorsión y se ha roto. Prosigue su afrenta de desmoronar lo lineal, de destrozar la "sucesión de los eventos, en todos los niveles de integración: "físico, biológico, social e individual" (Elias, 1989: 24). Mientras tanto, el árabe le recuerda a través de las telas lo efímero que es el tiempo y que aun en este lugar la sigue persiguiendo, a lo cual la narradora-protagonista contesta: "yo no quiero cosas muertas, quiero lo que perdura, no lo efímero ni lo transitorio" (Dávila, 2009: 66). La escena con el árabe termina cuando este dice: “... hasta que usted ya no pueda moverse ni respirar, así, así, así...” (Dávila, 2009: 68), simulando una especie de ahogo, pero también es un salto antes de una supuesta muerte, este salto la lleva al siguiente paraje.

Al salvarse del fin de su cronos, nos cuenta sobre un momento en su niñez cuando pierde parte importante de su inocencia al presenciar a un borrego degollado. El símbolo del borrego puede leerse como una analogía con la figura pura y pueril de la niña, sin embargo, la descripción del sacrificio del borrego - “Mamá, mamá, ¿por qué mataron al borrego?, le salía mucha sangre caliente, yo la cogí, mamá, allí en el patio" (Dávila: 2009: 68) - elabora un paralelismo con la pérdida de la niñez. La protagonista pierde pulcritud - "Sangre, iqué feo el olor de la sangre! Tibia, pegajosa, la cogí y me horroricé, me dio mucho asco y me limpié las manos en el vestido" (Dávila, 2009: 68) - lo que podemos entender como el tránsito de la infancia a una edad adulta donde se pierde inocencia e ingenuidad por factores de la propia madurez. Así, su niñez termina: "Me lavaron y pusieron otro vestido" (Dávila, 2009: 68). Esta última oración también la podemos entender como el iniciar de otra etapa de su vida.

Pese a que nos presenta diferentes escenarios, la narradora-personaje termina siempre por enfrentar a su antagonista, el tiempo es invencible: se puede matar a "El huésped»", puede desaparecer y encontrar la "Muerte en el bosque", incluso escabullirse del desconocido que llega a su casa y comprar "Un boleto para cualquier parte"; 4 pero la protagonista se enfrenta a la imposibilidad de escapar del tiempo: "Dávila siente la angustia ante el transcurso del tiempo

\footnotetext{
${ }^{4}$ Las comillas hacen referencia a cuentos de la autora zacatecana dentro del mismo compendio, ver Bibliografía.
} 
lineal y refleja su intento de «destrozar el tiempo» en su mundo literario" (Seong 2009: 7). "Tiempo destrozado" es un ejercicio contra el tiempo mismo, nos enseña el anhelo de detenerlo, de desafiarlo, de demostrar que al menos en la narrativa podemos alterar su orden, aunque sea como juego literario: "el sistema de lo fantástico no depende directamente de una tipología o clasificación temática, sino de una estrategia textual; no se trata del tema, sino de cómo se trata un tema" (López Casas, 2016: 57), así, el tiempo destrozado que se nos presenta en la narración alude a lo fantástico como una manera de huir de lo efímero quebrantando el orden natural de las acciones para escapar de una realidad que perece.

En la última escena del relato se nos narra la vejez del personaje principal. La acción se da a través de una descripción especular: "La mujer miraba por la ventanilla; de pronto se dio cuenta de mi presencia y se me quedó mirando fijamente. Era yo misma, elegante y vieja” (Dávila, 2009: 69). El tránsito por la vida comienza a llegar a su fin, el miedo a la última estación de la vida y la negación del fin del camino se hacen presentes. El tiempo, con el aviso de su presencia constante, toma la ventaja y somete a la víctima:

Sentí frío y terror de no tener ya rostro. De no ser más yo, sino aquella marchita mujer llena de joyas y de pieles. Y yo no quería ser ella. Ella era ya vieja y se iba a morir mañana, tal vez hoy mismo. Quise levantarme y huir, bajarme de aquel tren, librarme de ella. La mujer vieja me miraba fijamente y yo supe que no me dejaría huir. (Dávila, 2009: 69)

Escapar del tiempo, huir a través del desdoblamiento, buscar el reflejo y habitar en él. Si no pudo detenerlo, sí intentará evadirse de este: "Entonces una mujer gorda, cargando a un niño pequeño, vino a sentarse a mi lado. La miré buscando ayuda. También era yo aquella otra. Ya no podría salir, ni escapar, me habían cercado" (Dávila, 2009: 70).

Al mirarse en sus estadios — anciana, adulta, niña—, el personaje colapsa y huye al único lugar donde estará sin el tiempo mismo; quizá exista la tormenta, quizá se libere. Se trata de desafiar la marcha del tiempo. El tiempo es el horror de la protagonista, su adversario está en todos lados. Queda la pregunta, ¿en esta otra vida podremos destrozarlo? "La madre, yo misma, le tapaba la boca con un pañuelo morado y casi lo ahogaba. Sentí profundo dolor por el niño, ¡mi pobre niño!, y di un grito, uno solo" (Dávila, 2009: 70). Escapar del tiempo, transfigurarse: el tiempo encontró a la niña, a la mujer. La muerte inexorable viene por ella, pero antes del suceso y asimilándose en los otros, da un salto para burlar al enemigo: "El pañuelo con que tapaban [ahora el niño, su niño, ella] la boca era enorme y me lo metían hasta la garganta, más adentro, más..." (Dávila, 2009: 70). Así, como empezó su viaje al fondo del estanque y se ahogó para vivir, de la misma manera escapa esta vez del tiempo por medio de otro ahogamiento en el que "el área de acción cada vez es más pequeña: estación, tren, vagones, último vagón, asiento, brazos de la protagonista que se ahoga a sí misma" (García Cárdenas, 2010: 168). El relato termina con la palabra "más", y es precisamente con la misma palabra que comienza su viaje al fondo del estanque y que utiliza para describir su entrada a la otra existencia. En esta última escena dentro del tren, que puede ser el tren de la vida, se da un énfasis a la palabra "más", como si se tratara de remarcar una conexión con un volver de nueva cuenta y comenzar a jugar con la probabilidad de destrozar el tiempo, superviviendo esta inacabable sucesión de movimientos. 
El incesante flujo del acontecer no aplica en la trama del cuento. La narradoraprotagonista intenta destrozar el tiempo en su relato al realizar estos saltos de escenario en movimientos perpetuos en franca huida o liberación. El entramado, el incesante flujo del acontecer puede quebrarse y transgredirse, el transcurso de este viaje en el cuento supera la ley de la naturaleza perecedera.

\section{3. "El espejo": reflejo de lo fantástico y el interior de los protagonistas}

El cuento "El espejo" se apoya en lo que Ana María Barrenechea menciona como otra de las características que encierra lo fantástico: "Relaciones entre los elementos de este mundo, que rompen el orden reconocido: tiempos; espacios; causalidad; distinción sujeto/objeto. Esta última distinción podría comprender los iconos o simulacros: los sueños, los espejos y reflejos" (1972: 401). Así, la trama de este cuento nos presenta a la protagonista quien es una señora de edad avanzada, la cual vive con su hijo, un inspector de ventas en una compañía trasnacional. La señora sufre una fractura de pierna al mismo tiempo que su heredero debe salir por tres semanas a un viaje fuera del país, pero este último la deja en un "buen sanatorio, al cuidado de una enfermera especial" (Dávila, 2009: 71). No obstante, la estadía en el sanatorio no trae descanso para la mujer, pues existe un espejo en un ropero que a media noche se convierte en un tipo de portal. La mujer no puede descansar y su estabilidad física y mental se encuentra al borde, lo anterior lo constata el hijo a su regreso, ya que "Cuando ella me vio lanzó un extraño grito, que no era una exclamación de sorpresa ni de alegría. Era el grito que puede dar quien se encuentra en el interior de una casa en llamas y mira aparecer a un salvador" (Dávila, 2009: 72). Los días pasan y el hijo observa cómo su progenitora se encuentra "pálida y demacrada, y sus manos inquietas y temblorosas delataban el estado de sus nervios" (Dávila, 2009: 72). Entonces, el hijo habla con el médico, pero el galeno menciona que lo que tiene la paciente es la impresión del accidente sufrido y que su alteración puede ser un lapso normal. Al día siguiente, la madre cuenta a su vástago lo que sucede por las noches:

Tragué la píldora y en ese momento, no sé por qué, miré hacia el espejo del ropero y... —mamá interrumpió bruscamente su relato y se cubrió la cara con las manos. Traté de calmarla acariciándole los cabellos. Cuando se descubrió la cara y pude ver sus ojos un estremecimiento recorrió mi cuerpo. Permanecimos un rato en silencio como dos extraños, uno frente al otro. No le pregunté lo que había pasado, ni lo que había visto o creído ver en el espejo. Real o imaginario, debía ser algo tremendo para lograr desquiciarla hasta ese grado. (Dávila, 2009: 73)

Después de eso, el narrador (que es el hijo de la protagonista) pide cambiar a su progenitora de hospital, pero debido a su estado actual era imposible, lo mismo intentó cambiarla de habitación, sin embargo, los demás cuartos no resultaban tan limpios y eran deprimentes. Decide cambiar de enfermera, los días se suceden "- - Y bien, ¿te ha sido simpática la nueva enfermera? —Sí. Es educada, atenta, pero... — ¿Pero qué...? — Sigue sucediendo lo mismo. No es ella ni la otra. Nadie tiene la culpa, es el espejo, el espejo..." (Dávila, 2009: 74). El espejo del cuento rompe por completo la rutina de los protagonistas y de algo cotidiano y asimilable como un espejo en un ropero, surge una disociación entre sujeto y objeto que nos adentra al terreno de 
lo fantástico. A propósito del espejo, Carmen Noemí Perilli menciona en su artículo "El símbolo del espejo en Borges" lo siguiente:

Tradicionalmente los espejos son símbolos del alma, de la sombra y del espíritu. Como todo símbolo, el espejo tiene un carácter ambivalente y encierra significaciones opuestas. El símbolo del espejo remite a la certeza, aunque hecha de fugacidad y apariencia, de la posesión de nuestro propio ser, pero, por su ambigüedad, alude al mismo tiempo a la fascinación y al terror que experimentamos ante nuestras imágenes inconscientes. (1983: 149-50)

El espejo nos otorga nuestro reflejo y el de nuestra realidad, hace que nos reconozcamos y nos brinda pautas para el autoconocimiento; sin embargo, ese mismo reflejo hace cuestionarse a los personajes davilianos sobre lo que habita detrás de él, sobre quiénes los puedan estar observando. En la protagonista se originan tensión, ansiedad y sufrimiento a tal punto que comienza a padecer un trastorno del sueño, lo que hace agravar más su situación. Su recuperación se trunca y no logra volver a la tranquilidad. Ante la inseguridad y angustia crecientes, comienza a tratar de formular lo que se encuentra del otro lado del reflejo. La estabilidad que tanto su heredero como la rutina le otorgaban, ahora se tambalea y emerge lo inconcebible. Así, la literatura fantástica nos descubre la falta de validez absoluta de lo racional y "la posibilidad de la existencia, bajo esa realidad estable y delimitada por la razón en la que habitamos, de una realidad diferente e incomprensible, y, por lo tanto, ajena a esa lógica racional que garantiza nuestra seguridad y tranquilidad" (Roas, 2001: 9). La casa, sus costumbres, la repetición de su quehacer diario; forman un patrón que, al verse desequilibrarlo, resquebraja los soportes de su estadio cotidiano convencional debido a la ruptura ajena a toda lógica, no solamente amenaza su estabilidad, se apodera de ella.

Lo anterior también lo podemos encontrar como una de las características del símbolo que nos menciona Mauricio Beuchot: "algo concreto que nos lleva a algo abstracto, algo empírico que nos lleva a algo trascendental, o, finalmente, algo natural que nos lleva a algo sobrenatural" (2007: 15-16). Son precisamente en estas enunciaciones donde nuestros protagonistas se han quedado cautivos. Ellos confían que el espejo les devuelva el reflejo para concretar la realidad; no obstante, el espejo en el ropero no regresa la imagen natural que esperan, sino que les muestra formas sobrenaturales. Entonces, los protagonistas se sumergen en una situación abstracta que no pueden entender, que no conocen, pero que existe dentro del espejo. El miedo a lo desconocido, a lo que no pueden nombrar, los va arrastrando al abismo que se representa a través de ese lugar dentro del reflejo. Las posibilidades de encontrar sentido a lo que están viviendo se agotan y surgen abruptamente los peores temores: "En ese momento mamá gritó. Miré al espejo, allí no se reflejaba la imagen de Eduviges. El espejo estaba totalmente deshabitado y oscuro, ensombrecido de pronto. Después experimenté un gran vacío dentro de mí igual que en el espejo" (Dávila, 2009: 76). Esta sensación que acosa a los protagonistas es un lazo empático que los une y destruye. La necesidad que ambos poseen para responsabilizar al otro de su estado de salud físico y mental los ha llevado a confrontarse, pero no de una manera directa, sino que construyen un enemigo "ajeno", para "salvar" al otro de su propia responsabilidad; así, madre e hijo no pueden temerse o evadirse directamente, pero sí pueden enfrentar su trastorno en el reflejo de otro: 
Asistimos a un juego de posesión, en el cual las dos faceras del individuo luchan entre sí por apropiarse del contrario. Pero se trata de una lucha desigual, porque el reflejo fantástico e imaginario de la interioridad de personaje ha surgido para resolver la incapacidad de la razón a la hora de explicar la totalidad de la vida. En una atmósfera de fronteras imprecisas, los personajes dirimen su conflicto posesivo, absorbente y dramático, hasta que el más fuerte —el más libre“engulle” al otro y establece sus nuevos límites. (Núñez Esteban—Samblancat Miranda, 1995: 90)

Pero aquí también, este mismo estímulo sensorial indescriptible comienza a fermentarse en el lector: "Ante la incapacidad de los personajes por describir lo que ven y lo que sienten, el lector trata de llenar esos huecos con información pertinente: partiendo de sus referentes personales, pero dentro del contexto del discurso" (Herrera, 2015: 271). El abismo que describe la literatura fantástica nos concierne a todos ya que participamos en su construcción y se relaciona con nuestra cotidianeidad: "lo fantástico conlleva siempre una proyección hacia el mundo del lector, pues exige una cooperación y, al mismo tiempo, un envolvimiento del lector en el universo narrativo" (Roas 2001: 27). Este espejo es una puerta que se abre hacia lo insondable; más allá de lo que habita en su dimensión, está aquello que no se puede ver, es el terror a lo desconocido: ¿qué formas tan terribles pueden existir que no podemos concretarlas? Esta necesidad que no puede satisfacerse es lo que causa con mayor intensidad el sentimiento de agobio en los personajes. La cara material del espejo en el ropero y el reflejo de los personajes pueden describirse; el lado oscuro y ensombrecido, lo que yace dentro, su formulación incompleta da un resultado abominable: "Ahora tenía la casi seguridad de que de aquel vacío, de aquella nada, iba a surgir algo, no sé qué, pero algo que debía ser inaudito y terrible, algo cuya vista ni yo ni nadie podría soportar" (Dávila, 2009: 76).

Los protagonistas del cuento acuerdan tapar el espejo con una sábana. No ordenan cambiar el mueble, no lo giran o rompen: lo cubren. Tanto la madre como el hijo abandonan cualquier solución razonable; se entregan a la probabilidad de lo fantástico y desconocido. Deciden cubrir el espejo con una sábana; ¿acción instintiva, curiosidad por saber? Esta acción pueril demuestra la solución de sus problemas, no pueden armar su miedo, entonces lo niegan, y en esta negación tratan de exterminarlo, pero la tensión no desaparece, pues no saben si con este procedimiento ha dejado de existir lo que habita dentro o se encuentra mirándolos a punto de atacarlos en la obscuridad:

Pero de pronto, bajo la sábana que cubría el espejo, empezaron a transparentarse figuras informes, masas obscuras que movían angustiosamente, pesadamente, como si trataran en un esfuerzo desesperado de traspasar un mundo o el tiempo mismo. Entonces sentimos una oscura música dentro de nosotros mismos, una música dolorosa, como gemidos o gritos, tal vez sonidos inarticulados salidos de aquel mundo que habíamos clausurado por nuestra voluntad y temor. Nos descubrimos traspasados por mil espadas de música dolorosa y desesperada. (Dávila, 2009: 77)

Las sombras detrás de las sábanas mitigaron su horror. Los protagonistas ahora saben, aunque no se han despejado de su espasmo y miedo, pero tienen una respuesta: "los dos conocimos entonces toda nuestra insensatez. No volvimos a cubrir más el espejo. Habíamos sido elegidos y, como tales aceptamos sin rebeldía ni violencia, pero sí con la desesperanza de lo irremediable" (Dávila, 2009: 78). La aceptación o una extraña empatía fue el vehículo que los 
llevó de un estado de horror y desconocimiento a otro donde pudieran comenzar a entender lo que aquellas formas deseaban comunicar: "Aquellas sombras informes y encarceladas, aquella su lucha desesperada e inútil, nos habían hecho pedazos interiormente. Los dos conocimos entonces toda nuestra insensatez" (Dávila, 2009: 77-78). La soledad y el dolor se juntaron y fue la comunicación que necesitaban para sobrellevar su condición, madre e hijo: "acaban por convencerse de que han sido elegidos por un poder funesto y superior para ser testigos del sufrimiento de esas almas en tormento" (Negrete Sandoval, 2019: 185). Fueron los elegidos, ya que tanto las enfermeras como los doctores eran incapaces de ver lo que ellos presenciaban todas las noches. Con este lazo empático pueden concretar una relación directa con el símbolo; ya no es tan ajeno y peligroso, les da una parte de su significación para que logren vivir con él y compartirse su dolor y su soledad.

En los párrafos anteriores se desarrolló la configuración realidad-supernatural del relato, aquella que describe la vida de los protagonistas con el universo habitado por entidades que no moran en nuestra dimensión cotidiana espacio-tiempo. "El espejo" se forma con una parte oculta y nebulosa compuesta por las "masas oscuras", y se enlaza con otra parte que es develada y diáfana, representada por el acontecer de los protagonistas: lo simbólico como epicentro en la historia fantástica. La construcción simbólica que nos ofrece el cuento "El espejo" permite su reconfiguración mediante otras interpretaciones. A continuación, se elaborará un análisis al tomar la figura del espejo como un reflejo de la interiorización de los protagonistas.

En su artículo "Caretas, trajes y espejos", Antonia Amo Sánchez menciona lo siguiente acerca del efecto especular: "mirarse a sí mismo representa la indagación o introspección del hombre consigo mismo, que conduce a la retrospección íntima, al cuestionamiento del pasado y de sus consecuencias en un presente que puede, a su vez, condicionar el futuro" (2012: 173); ¿cabe la posibilidad de que el espejo no sea un portal hacia lo desconocido, sino un reflejo del interior de los personajes? La protagonista no tiene nombre propio. "Madre", "señora" son los nominativos por los cuales nos damos cuenta de su apariencia; así, la masculinidad del hijo (el cual es el narrador) y su desenvolvimiento dentro de la trama existen gracias a su progenitora. Empero, las enfermeras, quienes son las otras que interactúan dentro de la trama, sí poseen nombres propios: Lulú y Eduviges. El espejo nos puede estar dando el aspecto del interior de los personajes principales.

En lo concreto y en la información que recibimos del mismo relato, las enfermeras cumplen una labor social y humanitaria; pueden ser configuradas a través de ellas mismas y su papel laboral; pero la protagonista fue despojada de su papel como esposa. Como madre, al irse su heredero, pierde la identidad que poseía debido al alejamiento de su consanguíneo. El hijo (que tampoco tiene nombre propio), aunque sea "Inspector de ventas, valioso elemento, con un magnífico sueldo" (Dávila, 2009: 71) que trabaja en una empresa trasnacional, vive aún en el seno materno, sin familia o condominio propio, preocupado solamente por su bienestar y el de su progenitora. Entonces, no es aventurado pensar que, ante el desmoronamiento de su progenitora, él pierda estabilidad emocional. Ha fallado en su papel de protector y buen hijo. Al regreso, después de la separación, madre e hijo se observan como entes fallidos en su vida independiente. Son un espejo del otro donde se refleja la condición de soledad y desamparo en el que se 
encuentran: "Desde entonces nos identificamos de tal modo que llegamos a ser una sola persona y jueces severos uno del otro" (Dávila, 2009: 72). La separación de esta unidad trajo consigo desolación, soledad y abandono; los protagonistas, en su reencuentro, asimilan sus lazos psíquicos y sensoriales como una representación lastimada de su vida en aislamiento:

El mundo real pierde límites y se impregna de contenidos oníricos, de evocaciones simbólicas y de frustraciones vivenciales escondidas en el subconsciente. De esta manera, la manifestación visible de ese malestar no asumido adopta la apariencia de un nuevo personaje, caracterizado por lo elementos opuestos al personaje real, que cuestiona la primacía en la determinación de la voluntad del sujeto. (Núñez Esteban-Samblancat Miranda, 1995: 90)

Es en la cita anterior de Núñez Esteban y Samblancat Miranda donde podemos soportar la idea de que, al momento del desprendimiento filial, los sentimientos de desamparo, soledad, miedo, entre otros, afloran; crean un tormento que hace a la mujer transgredir su frontera con la realidad. Esta disposición en la que se encuentra la protagonista le producen alucinaciones (o “contenidos oníricos"), las cuales se proyectan en un espejo. Además, el heredero se ve a sí mismo en la imagen deteriorada de la madre, ambos se han transformado en el espejo del otro. Por ello, las mismas manifestaciones son producidas en su interior, entonces, estas formas especulares donde participan los protagonistas se presentan a modo de una monstruosidad compartida. Las imágenes (en este caso, el reflejo) de las "figuras informes, masas oscuras" (Dávila, 2009: 77) no figurarían como entes de otra dimensión, sino como un reflejo de la relación patológica madre-hijo, es una exteriorización de un horror contemplativo en el espejo: una simulación grotesca de la pareja.

Si los protagonistas observan que, a través del espejo, surgen criaturas en sufrimiento "como gemidos o gritos, tal vez sonidos inarticulados salidos de aquel mundo" (Dávila, 2009: 77), el efecto especular no hace más que devolverles esa extraña orientación que lleva el flujo de sus vidas. Las entidades informes, oscuras y angustiadas son un reflejo de los protagonistas: "En consecuencia, los personajes de la autora zacatecana no sólo se enfrentan con el otro exterior amenazante, sino también con una suerte de alteridad interior, hecho que contribuye igualmente al engendramiento de la ambigüedad, característica común de sus relatos" (Báder, 2019: 437). Dentro de esta situación, los protagonistas se sitúan en una realidad codependiente y sentenciada ante la abrumadora visión del espejo.

\section{Cierre}

Lo fantástico y lo simbólico dentro del cuento de Amparo Dávila nos sumergen dentro de las probabilidades de una trama interpretativa. En "Tiempo destrozado", el tiempo se toma como un antagonista simbólico, el cual se desenvuelve en dos facetas: tiempo mortal que es lineal, y un tiempo destrozado, resultado del quiebre de las sucesiones físicas del acontecer. La trama se compone de lo anterior como saltos que evaden la muerte, lo que nos lleva a un constante renacer de la protagonista en su osadía de transgredir el cronos. 
Asimismo, dentro de "El espejo" planteamos dos posibilidades de acercamiento a la trama; la primera, el antagonista como ente que rompe el orden conocido, como portal hacia otra realidad donde también se refleja el sufrimiento y la desolación de ese mundo; y una segunda interacción: como el reflejo del interior de los personajes y su codependencia que los daña. De esta forma, Amparo Dávila, muestra en su narrativa situaciones complejas que nos plantean lo fantástico como soporte de una realidad.

\section{Bibliografía}

ALIGHIERI, Dante (2003): La Divina Comedia. Pról. Jorge Luis Borges. México, Editorial Océano.

AMO SÁNCHEZ, Antonia (2012): “Caretas, trajes y espejos: elementos de grotesquización en el teatro de Charo González Casas". Signa, Revista de la Asociación Española de Semiótica, 21: 161-176. DOI: http://dx.doi.org/10.5944/signa.vol21.2012.6304

BÁDER, Petra (2019): "La representación del cuerpo como vertiente de la ambigüedad en la narrativa de Amparo Dávila”. En Claudia L. Gutiérrez Piña-Jazmín G. Tapia VázquezRogelio Castro Rocha (coords.): Un mundo de sombras camina a mi lado. Estudios críticos de la obra de Amparo Dávila. Guanajuato-México, Universidad de Guanajuato-Editorial Colofón: 421-441.

BARRENECHEA, Ana María (1972): "Ensayo de una tipología de la literatura fantástica". Revista Iberoamericana, XXXVIII/80: 391-403. DOI: http://dx.doi.org/10.5195/REVIBEROAMER.1972.2727

BEUCHOT, Mauricio (2007): "Símbolo, analogía e iconicidad". Hermenéutica analógica, símbolo, mito y filosofía. México, Universidad Nacional Autónoma de México: 13-24.

CARRERA GARRIDO, Miguel (2018): "Silencios y metáforas: analogías en el uso de la ambigüedad en «El huésped» de Amparo Dávila y el cine de terror (pos)moderno". Brumal. Revista de Investigación sobre lo Fantástico, VI/2: 187-206. DOI: https://doi.org/10.5565/rev/brumal.516

DÁVILA, Amparo (2009): Cuentos reunidos. México, Fondo de Cultura Económica.

DE HIPONA, Agustín (2015): Confesiones. España, Editorial Verbum.

ELIAS, Norbert (1989): Sobre el tiempo. Trad. Guillermo Hirata. México, Fondo de Cultura Económica.

GARCÍA CARDENAS, Lidia (2010): "El simbolismo del espacio en Tiempo destrozado". En Oriel Flores Flores-Gloria I. Vergara Mendoza (coords.): Ocho escritores latinoamericanos del siglo XX. México, Universidad Autónoma Metropolitana, Unidad Azcapotzalco: 149-199.

HERRERA, Jorge Luis (2015): "Lo grotesco y lo incomprensible. Fuentes de la violencia en «El espejo» de Amparo Dávila”. En Miguel Carrera Garrido-Mariola Pietrak (coords.): Narrativas de la violencia en el ámbito hispánico: guerra, sociedad y familia. Sevilla: Padilla Libros: 259-273. 
HERRERO CECILIA, Juan (2000): Estética y pragmática del relato fantástico: las estrategias narrativas y la cooperación interpretativa del lector. Cuenca, Universidad de Castilla-La Mancha.

LÓPEZ CASAS, Cristina (2016): "La evolución de lo fantástico en México: Daniel Lezama". Brumal. Revista de Investigación sobre lo Fantástico, IV/2: 45-80.

LOVECRAFT, Howard Phillips (2014): Supernatural Horror in Literature. Adelaide, The University of Adelaide. E-book, disponible en: http://ebooks.adelaide.edu.au/l/lovecraft/hp/supernatural/index.html (última consulta: 30/12/2019).

NEGRETE SANDOVAL, Julia Érika (2019): “El sustrato romántico en «La señorita Julia» y «E1 espejo» de Amparo Dávila. En Claudia L. Gutiérrez Piña-Jazmín G. Tapia VázquezRogelio Castro Rocha (coords.): Un mundo de sombras camina a mi lado. Estudios críticos de la obra de Amparo Dávila. Guanajuato-México, Universidad de Guanajuato-Editorial Colofón: 165-190.

NÚÑEZ ESTEBAN, Carmen-Neus SAMBLANCAT MIRANDA (1995): "Los espejos del yo en la narrativa de Cristina Fernández Cubas". Lectora. Revista de Dones i Textualitat, 1: 89-93.

PERILLI, Carmen Noemí (1983). "El símbolo del espejo en Borges”. Revista Chilena de Literatura, 21: 149-157.

RICCEUR, Paul (2003): El conflicto de las interpretaciones: ensayos de hermenéutica. Trad. Alejandrina Falcón. México, Fondo de Cultura Económica.

ROAS, David (2001): “La amenaza de lo fantástico". En --- (comp.): Teorías de lo fantástico. Madrid, Arco Libros: 7-46.

--- (2009): "Lo fantástico como desestabilización de lo real: elementos para una definición". En Teresa López Pellisa-Fernando Ángel Moreno Serrano (eds.): Ensayos sobre ciencia ficción y literatura fantástica: actas del primer Congreso Internacional de Literatura Fantástica y Ciencia Ficción. Madrid, Asociación Cultural Xatafi-Universidad Carlos III de Madrid: 94-120.

SEONG, Yu-Jin (2009): "Amparo Dávila y su arte en Tiempo destrozado". En Judith Podlubne (coord.): Actas del II Congreso Internacional "Cuestiones Críticas". Rosario: Centro de Estudios de Literatura Argentina-Centro de Teoría y Crítica de la Facultad de Humanidades y Artes de la Universidad Nacional de Rosario: http://www.celarg.org/int/arch_publi/seong_yu jin acta.pdf (última consulta: 20/12/2019).

TODOROV, Tzvetan (1981): Introducción a la literatura fantástica. Trad. Silvia Delpy. México, Premia.

(C) Iram Isaí Evangelista Ávila 


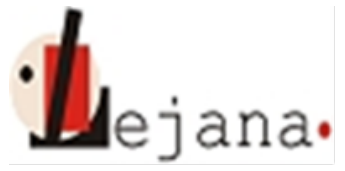

http://ojs.elte.hu/index.php/lejana

Universidad Eötvös Loránd, Departamento de Español, 1088 Budapest, Múzeum krt. 4/C 